\title{
Involvement and interactions of different immune cells and their cytokines in human visceral leishmaniasis
}

\author{
Pradyot Bhattacharya ${ }^{[1]}$ and Nahid Ali ${ }^{[1]}$
}

[1]. Infectious Diseases and Immunology, Indian Institute of Chemical Biology, West Bengal, India.

\begin{abstract}
Visceral leishmaniasis (VL) or kala-azar, a disseminated infection of the lymphoreticular system of the body, is marked by severe defect in immune system of the host. Successful cure of VL depends on the immune status of the host in combination with the effects of the antileishmanial drugs. The rationale approach towards eradication of this disease would be to potentiate the immune functioning of the host in addition to parasite killing. This review deals with different aspects of adaptive and innate immune responses and explores their role in protection or pathogenesis of VL. IL-10 has emerged as the principal cytokine responsible for disease pathogenesis, although evidences regarding its source during active VL remain inconclusive. On the other hand, IFN $\gamma$, under the influence of IL-12, is mostly correlated with healing of the disease. Chemokines are important in mounting cell-mediated immune response as they can prevent parasite invasion in association with cytokines. Different types of T cells like CD4, CD8 and NK T cells also contribute to the immunology of this disease. In spite of conflicting reports, the role of regulatory $\mathrm{T}$ cells in VL pathogenesis is important. Recently discovered Th17 subset and its different members have been reported to perform diverse functions in the course of VL and leishmaniasis as a whole. Innate immune responses, depending on the cell types, are essential in early parasite detection and subsequent development of an efficient NK cell response. Immunotherapy targeting IL-10 could be looked upon as an interesting option for the treatment of VL.
\end{abstract}

Keywords: Immunity. Human visceral leishmaniasis. Cytokines. IL-10.

\section{INTRODUCTION}

Protozoans of the genus Leishmania are obligate intracellular parasites causing a broad spectrum of diseases collectively known as leishmaniasis. This has emerged as the third most prevalent parasite-borne disease worldwide after malaria and filariasis ${ }^{1}$. Manifestations of this disorder can range from less severe cutaneous leishmaniasis (CL) characterized by selfresolving local cutaneous lesions and mucosal leishmaniasis (ML) affecting the mucus membranes of mouth, nose and throat to the more serious visceral leishmaniasis (VL), which is potentially fatal. An estimated 12 million people worldwide have some form of leishmaniasis, and another 350 million people are at risk. There are approximately 0.5 million new cases of $\mathrm{VL}$ each year and over $90 \%$ of these occur in Brazil, Bangladesh, India, Nepal and Sudan, although these numbers are likely to be an underestimation since majority of the cases are not even reported in these and many of the other 88 endemic countries ${ }^{2}$.

VL, caused by Leishmania donovani and Leishmania infantum (named Leishmania chagasi in the américas) is characterized by persistent low grade fever, hepatosplenomegaly,

\footnotetext{
Address to: Dr. Nahid Ali. 4, Raja SC Mullick Road, Jadavpur Kolkata, 700032 West Bengal, India.

Phone: 9133 2499-5757; Fax: 9133 2473-5197

e-mail: nali@iicb.res.in

Received 08 October 2012

Accepted 18 February 2013
}

cachexia, pancytopenia and hypergammaglobulinemia. The parasite resides primarily within macrophages of the liver, spleen, and bone marrow, and the course of the disease indicates an underlying defect in immune defense mechanism of the host. Earlier reports on Leishmania infection suggested that immune response in human $\mathrm{CL}^{3,4}$ and $\mathrm{VL}$ were associated with an interaction of T helper 1 (Th1)/Th2 cytokines at both cellular ${ }^{5-8}$ as well as transcriptional ${ }^{9}$ levels and depleted lymphoproliferative responses ${ }^{7}$. This suppressive nature of the immune response during active VL was mostly specific to leishmanial antigens as tests for delayed-type hypersensitivity (Leishmanin or Montenegro tests) to these antigens were negative ${ }^{10}$. The major players of this response were interferon gamma (IFN $\gamma$ ) and interleukin-4 (IL-4) in case of both VL and CL. However, unlike CL the effects of these cytokines were more of a mixed type in case of VL. As the immunological studies progressed IL-10 emerged as the most potent factor for VL pathogenesis which is evident from recent observations at cellular ${ }^{11,12}$ and messenger RNA (mRNA) levels ${ }^{13}$. The scenario, however, remains the same for Th1 cytokines as current observations also report suppressed antigen specific IFN $\gamma$ and IL-12 production ${ }^{11,12}$ in active VL. The level of IFN $\gamma$ in serum, however, remains high $^{12,14,15}$, suggesting that their sources could be lymphoid organs where the parasite proliferates. Indeed studies confirm high IFN $\gamma$ mRNA expression in bone marrow ${ }^{16}$, lymph node ${ }^{9}$ and splenic ${ }^{13}$ aspirates. Thus, these studies broadly reaffirm the previously described ${ }^{17}$ interplay of Th1/Th2 cytokines during Leishmania infection. Investigation for the cellular specificity of these cytokines led to the discovery of the involvement of cluster of differentiation $4^{+}\left(\mathrm{CD} 4^{+}\right), \mathrm{CD} 8^{+}$and Natural Killer (NK) 
$\mathrm{T}$ cells in this disease. However, as with the earlier reports ${ }^{5,8,18}$ more recent observations ${ }^{19-24}$ also failed to distinguish these $\mathrm{T}$ cells based on their protective or pathogenic role in VL. Another T cell essential for this disease is regulatory T cell (Treg). Although the effect of $\mathrm{CD}^{+} \mathrm{CD} 25^{+} \mathrm{T}$ cells in disease progression has already been reported ${ }^{11}$, the role of $\mathrm{CD} 4^{+} \mathrm{CD} 25^{+} \mathrm{FoxP} 3^{+}$natural Treg cells in the disease pathology still remains a matter of debate ${ }^{13,25,26}$. Chemokines are important members of cellmediated immune response that exhibit antileishmanial activity through recruitment of different immune cells at infection sites (both liver and spleen). In leishmaniasis, both cytokines and chemokines interact closely to strengthen the host defense against parasite. IL-17, the signature cytokine for the recently discovered Th17 subset, was found to play a significant role in the migration, recruitment and activation of neutrophils. Since the neutrophils are known to have important regulatory and/or effector functions during Leishmania infection, Th17 can be looked upon as an important regulator for this disease. Indeed, there have been reports of involvement of different Th17 cytokines like IL-17, IL-22 ${ }^{27}$ and IL-2 ${ }^{28}$ in human VL. In addition to adaptive immune response innate immune response involving cells like dendritic cells (DCs), macrophages, neutrophil/eosinophil etc. are essential in regulating the initial entry of parasites. They are involved not only in preventing parasite invasion but also in controlling their multiplication through the release of different cytokines. This review will examine the interplay of different components of adaptive and innate immune responses and their involvement in disease or elimination of human VL.

\section{DIFFERENT CYTOKINES, CHEMOKINES AND CELLULAR SUBSETS: ROLE IN VL}

A close look at the progressive findings in the field of immunology of human VL suggests important roles of different cytokines in disease protection and pathogenesis. Few of the very first reports on VL immunopathogenesis regarded upregulation of IL-48,17 and IL-10 $0^{5}$ and loss of function of IFN $\gamma^{5-7,9}$ as the indication of active disease. In fact IL-4 was initially regarded as a marker for active disease ${ }^{8}$. However, later observations exhibited its mixed response towards VL. Whereas some reports indicated lower IL-4 levels in nodal and portal areas of in situ liver lesions as well as in serum during disease ${ }^{14}$ and its corresponding enhancement after cure ${ }^{19}$, others suggested enhancement of IL- $4^{+}$neutrophils in active $\mathrm{VL}^{29}$. As more investigations were carried out using different samples like tissue sections ${ }^{20}$, plasma ${ }^{14,15,18,19,30-33}$, whole blood ${ }^{34}$, peripheral blood mononuclear cells (PBMC) $)^{11,12,31,35,36}$, mRNA $^{35-37}$ and splenic aspirate cells ${ }^{38}$ more evidences emerged suggesting IL-10 to be the principal contributor for VL pathology. Results from flow cytometric studies of cytokines also supported this finding ${ }^{18,29}$. Post kala-azar dermal leishmaniasis (PKDL), a disease manifestation of VL, is also characterized by enhanced IL-4 ${ }^{14,39}$ as well as IL-10 expression and perhaps the subsequent masking effect exerted on IFN $\gamma$ by IL-10 is apparent from a generally heightened response of this cytokine $e^{9,11,14,39-41}$. Like IFN $\gamma$, IL-12 is also responsible for a protective response. In fact it influences the production of IFN $\gamma^{6,7,11,12,20,33}$ and the loss of lymphoproliferative response during active VL was formerly attributed to its lower expression ${ }^{6,7}$. As already mentioned this loss of lymphoproliferation could be looked upon as a failure of response towards Leishmania antigen and it has been proposed that PBMCs of VL patients might consist of a non-Leishmania antigen-specific population which fails to proliferate upon Leishmania antigen stimulation ${ }^{10}$. Although primarily protective, IFN $\gamma$ could sometimes be associated with disease exacerbating conditions as was evident in an alternate activation pathway of Th1 cells through Trp-Ser-X-1 (WSX-1) ligation which might also lead to activation of transcription factor for IL-10 $0^{42}$.

The mechanism of the suppressive activity of IL-10 in human VL was primarily attributed to reduction in migration inhibitory factor (MIF) regulated accumulation of monocytederived macrophages ${ }^{43}$ and inhibition of $\mathrm{NO}$ generation from macrophages resulting in downregulation of leishmanicidal activity ${ }^{44}$. Recently more insights have come up regarding IL-10 expression and regulation where its production from macrophages infected with $L$. donovani is reported to be negatively influenced by glycogen synthase kinase- $3 \beta$ (GSK-3 $\beta$ ). GSK-3 $\beta$ expression, on the other hand, is inhibited by either phosphatidylinositol-3 kinase (PI3K) or activated form of serine-threonine kinase $\mathrm{Akt}^{36}$. Another interesting observation has suggested that intracellular network of PI3K along with mammalian target of rapamycin (mTOR) signaling pathway regulate IL-10 modulation by L. donovani ${ }^{45}$.

IFN $\gamma$ and IL-10 might be the major players of VL pathology, but various other cytokines also have significant role in disease persistence. Some of them are traditionally known whereas others have emerged through progressive research. One such member, IL-6, was known to be associated with both active VL ${ }^{14,18,46}$ and PKDL ${ }^{14}$ conditions. It is an important pro-inflammatory cytokine related to Th2 differentiation ${ }^{47}$, inflammation and Th1 response ${ }^{48}$ as well as development of Th17 cells ${ }^{49}$. Thus IL-6 maintains a balance between $\mathrm{T}$ cell responses during active disease. Involvement of transforming growth factor beta (TGF $\beta)$ in VL pathology was earlier reported by Saha et al. ${ }^{11}$, which later on got confirmed by immunohistochemical observation of Kupffer cells ${ }^{50}$ and polymorphism study of a particular locus of $T G B 1$ gene $^{51}$. Mechanism of action of TGF $\beta$, in active $L$. donovani infection, was thought to be associated with overexpression of ubiquitin-editing enzyme A20 through tyrosine phosphatase response ensuring transient activation of inflammatory signaling pathways in macrophages ${ }^{52}$. It was also known to contribute towards PKDL manifestation ${ }^{11,14}$.

Another important cytokine tumor necrosis factor alpha (TNF $\alpha$ ), known for exerting cytotoxic effects on invading pathogens, along with its receptor TNFR is also closely associated with VL pathogenesis and PKDL manifestation. This was previously reported by Medeiros et al. ${ }^{53}$ and further

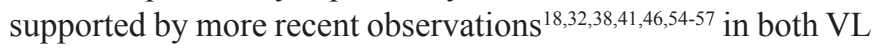
and PKDL patients. Unique cytokines have also emerged in implicating disease progression as recent observations indicate IL-27 to be the regulator of IL-10 producing T cells through induction of IL-21 ${ }^{28}$. 
Chemokines, which are chemotactic cytokines, also play crucial roles during Leishmania infection. They help in eliciting antileishmanial activity by promoting cell-mediated immune response through recruitment of different subsets of leukocytes at infection site and subsequently stimulating them. Members of the chemokine family involved in this process depend on the stage of infection and pathogens involved; the cell populations recruited at the early stage are essential in defining the outcome of the disease ${ }^{58}$. In one study elevated levels of chemokines, chemokine (C-X-C motif) ligand 9 [CXCL9] and CXCL10, were reported in serum during active infection and it was suggested that these chemokines along with IFN $\gamma$ play an important immunopathogenic role during disese $^{30}$. Since not many reports are available regarding the role of chemokines in human VL we will mainly discuss the importance of different chemokines in experimental VL models where they are known to mount a Th1 response through their influence on IFN $\gamma$ production. Indeed $L$. donovani infected mice lacking chemokine receptor chemokine (C-C motif) receptor 5 [CCR5] or its ligand macrophage inflammatory protein (MIP) $1 \alpha$ exhibits a low antigen-specific IFN $\gamma$ production during the initial phases of infection ${ }^{59}$. The higher expression of MIP- $1 \alpha$ along with chemokine (C-C motif) ligand 2 [CCL2] in liver cells of $L$. donovani infected mice during early stages of infection is responsible for the recruitment of monocytes. Monocytes thus recruited could produce Th1 mobilizing chemokine CXCL10 under the influence of IFN $\gamma$ at the late phase of infection enabling hepatic granuloma formation and lymphocyte recruitment ${ }^{60}$. L. donovani infection could also downregulate CCR7 expression, thereby impairing DC migration to draining lymph nodes and facilitating disease progression ${ }^{61}$. The scenario is somewhat different in spleen cells of $L$. infantum infected mice where Th2 type response predominates over Th1. This response is regulated by persistent CCL 2 expression suggesting that there is an invasion of macrophages rather than T cells in the spleen ${ }^{62}$.

Investigations are also being carried out to determine the source of these various cytokines so that particular cell types could be attributed to VL infection. Previously $\mathrm{CD}^{+8}$ and $\mathrm{CD} 8^{+5,63} \mathrm{~T}$ cell populations were reported to be major contributors of disease manifestation. They still remain so, however, further observations identify different CD4 sub-populations like chemokine receptor-5 (CCR5) ${ }^{+} \mathrm{CD} 4^{+64}$ and $\mathrm{CD} 2^{\text {low }} \mathrm{CD} 4^{+65}$ to be the markers of active VL. Human immunodeficiency virus (HIV) co-infection has emerged as a potent threat in VL patients and their involvement with different $\mathrm{T}$ cells is established with reports of higher CXCR4, a co-receptor of HIV, expression on $\mathrm{CD} 4^{+} \mathrm{T}$ cells ${ }^{66}$ and lower $\mathrm{CD} 8^{+} \mathrm{T}$ cell count ${ }^{67}$ in patients with HIV-VL. Subpopulations of $\mathrm{CD}^{+} \mathrm{T}$ cells also become important as lower expression of bone-marrow $\mathrm{CD} 8^{+} \mathrm{CD} 18^{+} \mathrm{CD} 45 \mathrm{RO}^{+}$ lymphocytes can be looked upon as the biomarker of acute $\mathrm{VL}^{68}$. NK T cells $\left(\mathrm{CD}^{+} \mathrm{CD} 161^{+} \mathrm{V} \alpha 24\right)$, formerly known for clearance of parasite from liver by direct and indirect $1 y \mathrm{sis}^{54}$ and playing a regulatory role in $\mathrm{VL}^{69}$, are also reported to produce IFN $\gamma$ in response to $L$. donovani antigens at the disease site $^{70}$.

Further exploration of the cellular origin of cytokines led to the discovery of a distinct $\mathrm{T}$ cell subset known as regulatory T cells (Treg). Elemental role of Treg cells include homeostasis and prevention of excessive inflammation mostly due to IL-10 production $^{71}$. These can be broadly divided into two categories: thymus derived $\mathrm{CD} 4^{+} \mathrm{CD} 25^{+} \mathrm{FoxP} 3^{+}$natural Treg (nTreg) cells, and inducible Tregs that are derived from periphery and are either FoxP3 ${ }^{+}$(iTreg) or adaptive FoxP3- type-I Treg cells (Tr1). There are contradictory reports regarding the role of nTregs in VL progression. Whereas some observations downplayed the importance of nTregs as the population responsible for IL-10 secretion and disease pathogenesis ${ }^{13,26}$, others suggested it to be the source of IL-1025. Role of $\mathrm{CD} 4{ }^{+} \mathrm{CD} 25^{+} \mathrm{T}$ cells in PKDL pathogenesis was reported by Saha et al. ${ }^{11}$ This observation was further extended in reports of enhanced lesional $\mathrm{CD}^{+} \mathrm{CD} 25^{+} \mathrm{FoxP} 3^{+}$expression in PKDL patients ${ }^{23}$. More conclusive evidences came from the demonstration of accumulated nTreg cells at infection site with a correlation of both IL-10 and nTreg levels with parasite burden, thus implying their role in disease severity in $\mathrm{PKDL}^{72}$.

\section{TH17 CELLS: SIGNIFICANCE IN PROTECTION AND PROGRESSION OF LEISHMANIASIS}

Th17 subset of $\mathrm{T}$ cells was only identified in 2005 and mainly associated with different autoimmune diseases like psoriasis, multiple sclerosis (MS), rheumatoid arthritis (RA) and inflammatory bowel disease (IBD) as well as allergic reactions including asthma ${ }^{73}$. Th17 cell lineage development is induced by cytokines such as IL-6, IL-23 and TGF $\beta^{49}$ which in turn activate the signal transducer and activator of transcription (STAT)3 pathway ${ }^{74}$ leading to the expression of the transcription factor retinoic-acid orphan related receptors (ROR- $\alpha$ and ROR- $\gamma \mathrm{t})^{71}$. Th17 cells mainly produce IL-17A and IL-17F cytokines, in addition to other cytokines such as IL-21 and IL-22 ${ }^{75}$. IL-17 performs an important function in neutrophil development and since neutrophils are regarded as an important effector during Leishmania infection, it would be possible that Th17 cells might have a significant role in this disease ${ }^{76}$. However, the exact function they perform in this disease depends largely on the parasite species and the genetic background of the host.

First report of the involvement of Th17 subset in human VL came from studies of Pitta et al. ${ }^{27}$ when they suggested that IL-17 and IL-22, along with Th1 cytokines, play complementary roles in protective response against VL and any defect in this mechanism could increase the risk of this disease. More recent observations, however, indicate IL-21 to be the part of a feedback control mechanism that could lead to the expansion of IL-10-producing T cells thereby representing its role as a disease-promoting cytokine ${ }^{28}$. Increased lesional expression of IL-17 and IL-23 in PKDL patients and their subsequent downregulation following cure establish the importance of Th17 cells in this disease ${ }^{41}$.

Since not many reports are available regarding the involvement of Th17 cells in human VL, we will include experimental VL as well as other forms of leishmaniasis in our discussion. Disease promoting role of IL-17 has been recognized in IL-17 deficient mice model of CL which show lesser infection severity than IL-17 positive mice. This effect was attributed mainly to IL-17 because comparable levels of other cytokines 
like IL-10, IFN $\gamma$ etc. was observed in both IL-17 positive and depleted mice whereas reduced neutrophil recruitment was reported only in IL-17 deficient mice ${ }^{77}$, thereby establishing the association between increased neutrophil recruitment and severity of disease.

Conflicting roles of IL-17 in disease pathology was also evident in other Leishmania species. Whereas studies with experimental models of $L$. braziliensis $^{78}$ and L. panamensis ${ }^{79}$ infections exhibited induction of healing in association with elevated IL-17 as well as IFN $\gamma$ levels, reports from human ML suggested that IL-17 was involved in ML pathogenesis ${ }^{80}$.

Vaccine studies provide evidence for the protective role of Th17 cells as live L. major plus CpG DNA vaccine led to enhanced proliferation of $\mathrm{CD} 4^{+} \mathrm{Th} 17$ cells thereby preventing lesion development and providing long-term immunity ${ }^{43}$. Similar observations were made in experimental VL where protection induced by $\mathrm{CpG}$ stimulated bone marrowderived DCs pulsed with $L$. infantum kinetoplastid membrane protein 11 (KMP-11) peptide was correlated with secretion of IL-1 $7^{81}$.

IL-27 is known to be an important regulator of the expression of Th17 cell lineage. It belongs to the IL-6/IL-12 cytokine family and its suppressive effect on Th17 subset was earlier reported in experimental autoimmune encephalomyelitis ${ }^{82}$ and murine influenza infection ${ }^{83}$. This observation was further extended in murine CL model where IL-27 was found to maintain a critical balance between disease protection and pathogenesis by inducing IFN $\gamma$ and IL-10 from CD4+ T cells and suppressing inappropriate Th17 development ${ }^{84}$. Interesting observations regarding IL-27/T-cell cytokine receptor (TCCR) pathway has been made for experimental VL where, unlike CL, disease resistance was linked to IL-27/TCCR ${ }^{-/}$rather than their wild-type counterparts ${ }^{85}$. However, these results were attributed to liver immunopathology and no Th17 component was examined.

\section{INNATE IMMUNE RESPONSE}

Innate immune response against Leishmania infection plays a pivotal role in predicting the outcome of the disease. It not only helps in preventing the early parasite growth and spreading of infection but also acts as a source of different immunoregulatory cytokines. Leishmania being an opportunistic parasite can employ several strategies for its survival inside the macrophage phagolysosomes. Macrophage, one of the major players of innate immunity, was primarily known to exert its effects against $L$. donovani infection through the production of inducible nitric oxide synthase (iNOS) in liver ${ }^{86}$. Although one report suggested the anti-parasitic effect of macrophages in liver to be iNOS-independent ${ }^{87}$, the mechanism by which it exerts its antileishmanial activity remained mostly iNOS-dependent in both liver and spleen ${ }^{88,89}$. Studies are, in fact, being carried out to discover the iNOS-independent parasiticidal mechanism of macrophages. Leishmania donovani, on the other hand, is known to evade the iNOS-dependent killing in macrophages through the induction of arginase 1 in an IL-10 mediated fashion ${ }^{90}$.
DCs, another important contributor of the innate response, can be of two types- myeloid (mDC) and plasmacytoid (pDC). Of these mDCs are known to exert cytotoxic effects on L. infantum parasites by producing IL-12 under the influence of Toll-like receptor (TLR) 9 and inducing NK cells to release IFN $\gamma^{91}$. pDCs, however, are unable to phagocytose parasites, but they can produce IL-12 in a TLR-9 dependent manner suggesting their relevance during later stages of infection ${ }^{91}$. Studies in VL patients suggested a reduced secretory activity of neutrophils and eosinophils attributable to the deficiencies in the production of their potent activators IL-8 and eotaxin, respectively ${ }^{92}$. Cytokines secreted by these cells during infection show a predominant $\mathrm{Th} 2$ response with an enhanced IL- $4^{+}$neutrophil and IL- $10^{+}$eosinophil and reduced IFN $\gamma^{+}$and IL- $12^{+}$eosinophil frequencies ${ }^{29}$ (Figure 1).

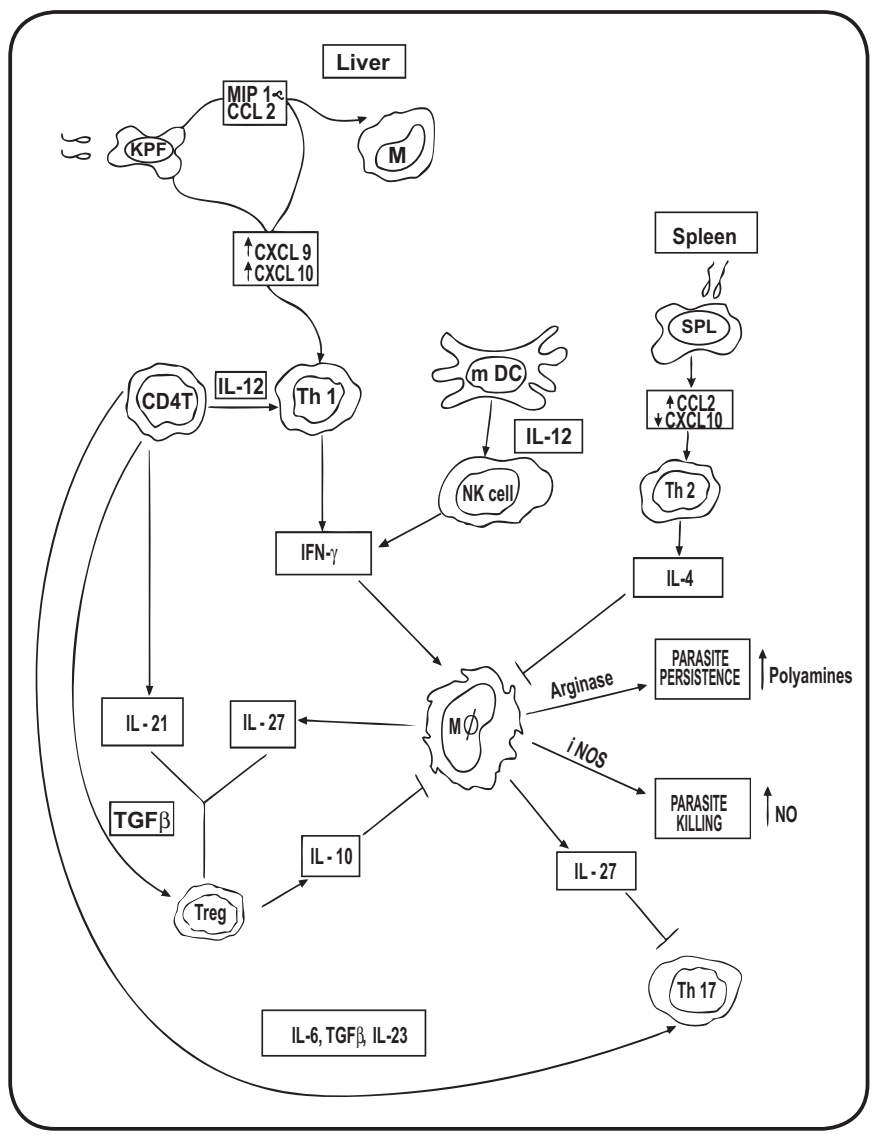

FIGURE 1 - Interaction of different components of innate and adaptive immune systems and their possible role in parasite persistence/clearance.

Rapid hepatic accumulation of chemokines CCL2, CXCL9, CXCL10 that occurs after infection leads to a Th1 response through IFN $\gamma$ and facilitates parasite clearance by macrophages. By contrast, in the spleen, a consistent expression of CCL2 leads to a dominance of Th2 cytokines and sustained parasite persistence. IL-12 produced by mDCs could activate NK cells to secrete IFN $\gamma$. IL-10 produced by Treg is the key factor for disease pathogenesis. IL-27, produced by macrophages, can suppress Th17 subset. It could also activate Treg cells in collaboration with IL-21 produced by CD4 T cells. KPF: Kupffer cells; SPL: spleen; M: monocyte; MIP-1 $\alpha$ : macrophage inflammatory protein1alpha; CCL: chemokine (C-C motif) ligand; CXCL: chemokine (C-X-C motif) ligand; CD: cluster of differentiation; IL: interleukin; Th: T helper; mDC: myeloid dendritic cell; NK: natural killer; M $\phi$ : macrophage; iNOS: inducible nitric oxide synthase; Treg: regulatory T cell; IFN $\gamma$ : interferon gamma; TGF $\beta$ : transforming growth factor beta. 


\section{CONCLUSIONS}

The immunological studies that have been carried out so far on human VL clearly identify IL-10 to be the most important factor for disease pathogenesis. The immunosuppressive effect exerted by this cytokine is mainly due to the deactivation of monocyte-derived macrophages promoting enhanced survival and growth of the parasite. However, the cellular sources responsible for its induction and the exact mechanism behind the establishment of persistent infection still remain unclear. Present chemotherapeutic approaches against VL are unsatisfactory due to the problems of resistance, toxicity and long-term hospitalization. Since successful treatment is thought to depend, in part, on potential immune functioning of the host, direct manipulation of the immune response, either alone or in combination with drugs, through neutralization/blockade of IL-10 and targeting of its cellular source(s) might be considered as a novel therapeutic intervention. Chemokines released after parasite invasion could attract different subsets of leukocytes. Whether these cells act as reservoir of the parasites or contribute to their virulence depends on the nature of chemokine involved. Thus developing inhibitors of the chemokine system could help us to explore the mechanism of immunopathogenesis.

Experimental observations regarding the involvement of Th17 subset with leishmaniasis clearly signify the importance of IL-22 and IL-23 along with IL-17. These studies also provide evidences against the so-far known purely pro-inflammatory role of Th17 cells. IL-27, known for its general suppressive effects on Th1, Th2 and Th17 subsets, has also emerged as an important cytokine as it could induce IL-10 production from Tr1 cells and inhibit effector $\mathrm{T}$ cells. Thus it would be interesting to further investigate the role of IL-27 and its downstream cytokine IL-21 in pathogenesis of VL. The control of $L$. donovani multiplication in the macrophages could be achieved by both iNOS-dependent and independent pathways depending on the stage of infection. The activation of NK cells in VL is the outcome of its close interaction with $\mathrm{mDCs}$, which are triggered by the parasites for the production of IL-12 in a TLR9-dependent fashion. The exact role of pDCs and their TLR9-dependent release of IL-12 require further investigation.

\section{CONFLICT OF INTEREST}

The authors declare that there is no conflict of interest.

\section{FINANCIAL SUPPORT}

Indian Council of Medical Research (ICMR), India and Council of Scientific and Industrial Research (CSIR), India.

\section{REFERENCES}

1. Pourahmad M, Hooshmand F, Rahiminejad M. Cutaneous leishmaniasis associated with visceral leishmaniasis in a case of acquired immunodeficiency syndrome (AIDS). Int J Dermatol 2009; 48:59-61.

2. World Health Organization. Control of the leishmaniases. World Health Organization technical report series 2010; (949):XII-XIII, p. 1-186.
3. Caceresdittmar G, Tapia FJ, Sanchez MA, Yamamura M, Uyemura K, Modlin RL, et al. Determination of the cytokine profile in american cutaneous leishmaniasis using the polymerase chain-reaction. Clin Exp Immunol 1993; 91:500-505.

4. Raziuddin S, Abdalla RE, Elawad EH, Aljanadi M. Immunoregulatory and proinflammatory cytokine production in visceral and cutaneous leishmaniasis. J Infect Dis 1994; 170:1037-1040.

5. Holaday BJ, Pompeu MMD, Jeronimo S, Texeira MJ, Sousa AD, Vasconcelos AW, et al. Potential role for interleukin-10 in the immunosuppression associated with Kala-Azar. J Clin Invest 1993; 92:2626-2632.

6. Bacellar O, Brodskyn C, Guerreiro J, BarralNetto M, Costa CH, Coffman RL, et al. Interleukin-12 restores interferon-gamma production and cytotoxic responses in visceral leishmaniasis. J Infect Dis 1996; 173:1515-1518.

7. Ghalib HW, Whittle JA, Kubin M, Hashim FA, Elhassan AM, Grabstein KH, et al. IL-12 Enhances Th1-Type responses in human Leishmania-donovani Infections. J Immunol 1995; 154:4623-4629.

8. Mary C, Auriault V, Faugere B, Dessein AJ. Control of Leishmania infantum infection is associated with $\mathrm{CD} 8(+)$ and gamma interferon- and interleukin-5producing CD4(+) antigen-specific T cells. Infect Immun 1999; 67:5559-5566.

9. Ghalib HW, Piuvezam MR, Skeiky YAW, Siddig M, Hashim FA, Elhassan AM, et al. Interleukin-10 production correlates with pathology in human Leishmaniadonovani Infections. J Clin Invest 1993; 92:324-329.

10. Goto H, Gracas M. Immunoactivation and immunopathogeny during active visceral leishmaniasis. Rev Inst Med Trop Sao Paulo 2009; 51:241-246.

11. Saha S, Mondal S, Ravindran R, Bhowmick S, Modak D, Mallick S, et al. IL-10- and TGF-beta-mediated susceptibility in kala-azar and post-kala-azar dermal leishmaniasis: The significance of amphotericin B in the control of Leishmania donovani infection in India. J Immunol 2007; 179:5592-5603.

12. Mondal S, Bhattacharya P, Rahaman M, Ali N, Goswami RP. A curative immune profile one week after treatment of Indian Kala-azar patients predicts success with a short-course liposomal amphotericin B therapy. Plos Negl Trop Dis 2010; 4:e764.

13. Nylen S, Maurya R, Eidsmo L, Das Manandhar K, Sundar S, Sacks D. Splenic accumulation of IL-10 mRNA in T cells distinct from CD4(+) CD25(+) (Foxp3) regulatory T cells in human visceral leishmaniasis. J Exp Med 2007; 204:805-817.

14. Ansari NA, Saluja S, Salotra P. Elevated levels of interferon-gamma, interleukin-10, interleukin-6 during active disease in Indian kala azar. Clin Immunol 2006; 119:339-345.

15. Khoshdel A, Alborzi A, Rosouli M, Taheri E, Kiany S, Javadian MH. Increased levels of IL-10, IL-12, and IFN-gamma in patients with visceral leishmaniasis. Braz J Infect Dis 2009; 13:44-46.

16. Karp CL, Elsafi SH, Wynn TA, Satti MMH, Kordofani AM, Hashim FA, et al. Invivo cytokine profiles in patients with kala-azar - marked elevation of both interleukin-10 and interferon-gamma. J Clin Invest 1993; 91:1644-1648.

17. Kemp M, Kurtzhals JAL, Kharazmi A, Theander TG. Interferon-Gamma and Interleukin-4 in Human Leishmania-donovani Infections. Immunol Cell Biol $1993 ; 71: 583-587$.

18. Lagler H, Willheim M, Traunmuller F, Wahl K, Winkler H, Ramharter M, et al. Cellular profile of cytokine production in a patient with visceral leishmaniasis: gamma delta $(+) \mathrm{T}$ cells express both type 1 cytokines and interleukin-10. Scand J Immunol 2003; 57:291-295.

19. Hailu A, van Baarle D, Knol GJ, Berhe N, Miedema F, Kager PA. T cell subset and cytokine profiles in human visceral leishmaniasis during active and asymptomatic or sub-clinical infection with Leishmania donovani. Clin Immunol 2005; 117:182-191.

20. Ghosh M, Mandal L, Maitra S, Rakshit S, Paul K, Bagchi J, et al. Leishmania donovani infection of human myeloid dendritic cells leads to a Th1 response in CD4(+) T cells from healthy donors and patients with kala- azar. J Infect Dis 2006; 194:294-301.

21. Narayan S, Bimal S, Singh SK, Gupta AK, Singh VP, Sinha PK, et al. Leishmania donovani vs immunity: T-cells sensitized from Leishmania of one donor may modulate their cytokines pattern on re-stimulation with Leishmania from different donor in visceral leishmaniasis. Exp Parasitol 2009; 121:69-75.

22. Luz KG, Tuon FF, Duarte MIS, Maia GM, Matos P, Oliveira Ramos AM, et al. Cytokine expression in the duodenal mucosa of patients with visceral leishmaniasis. Rev Soc Bras Med Trop 2010; 43:393-395. 
23. Ganguly S, Mukhopadhyay D, Das NK, Chaduvula M, Sadhu S, Chatterjee U, et al. Enhanced lesional Foxp3 expression and peripheral anergic lymphocytes indicate a role for regulatory $\mathrm{T}$ Cells in Indian post-Kala-Azar dermal leishmaniasis. J Invest Dermatol 2010; 130:1013-1022.

24. Santos-Oliveira JR, Regis EG, Leal CRB, Cunha RV, Bozza PT, Da-Cruz AM. Evidence that lipopolisaccharide may contribute to the cytokine storm and cellular activation in patients with visceral leishmaniasis. Plos Negl Trop Dis 2011; 5:e1198.

25. Rai AK, Thakur CP, Singh A, Seth T, Srivastava SK, Singh P, et al. Regulatory $\mathrm{T}$ Cells suppress $\mathrm{T}$ Cell activation at the pathologic site of human visceral leishmaniasis. Plos One 2012; 7:e31551.

26. Maurya R, Kumar R, Prajapati VK, Manandhar KD, Sacks D, Sundar S, et al. Human visceral leishmaniasis is not associated with expansion or accumulation of Foxp3+CD4 cells in blood or spleen. Parasite Immunol 2010; 32:479-483.

27. Pitta MGR, Romano A, Cabantous S, Henri S, Hammad A, Kouriba B, et al. IL-17 and IL-22 are associated with protection against human kala azar caused by Leishmania donovani. J Clin Invest 2009; 119:2379-2387.

28. Ansari NA, Kumar R, Gautam S, Nylen S, Singh OP, Sundar S, et al. IL-27 and IL-21 are associated with T Cell IL-10 responses in human visceral leishmaniasis. J Immunol 2011; 186:3977-3985.

29. Peruhype-Magalhaes V, Martins-Filho OA, Prata A, Silva LD, Rabello A, Teixeira-Carvalho A, et al. Immune response in human visceral leishmaniasis: Analysis of the correlation between innate immunity cytokine profile and disease outcome. Scand J Immunol 2005; 62:487-495.

30. Hailu A, Van der Poll T, Berhe N, Kager PA. Elevated plasma levels of interferon (IFN)-gamma, IFN-gamma inducing cytokines, and IFN-gamma inducible CXC chemokines in visceral leishmaniasis. Am J Trop Med Hyg 2004; 71:561-567.

31. Caldas A, Favali C, Aquino D, Vinhas V, van Weyenbergh J, Brodskyn C, et al. Balance of IL-10 and interferon-gamma plasma levels in human visceral leishmaniasis: Implications in the pathogenesis. BMC Infect Dis 2005; 5: 113 .

32. Gama MEA, Costa JML, Pereira JCR, Gomes CMC, Corbett CEP. Serum cytokine profile in the subclinical form of visceral leishmaniasis. Braz J Med Biol Res 2004; 37:129-136.

33. Kurkjian KM, Mahmutovic A, Kehar KL, Haque R, Bern C, Secor WE. Multiplex analysis of circulating cytokines in the sera of patients with different clinical forms of visceral leishmaniasis. Cytometry A 2006; 69A:353-358.

34. Singh OP, Gidwani K, Kumar R, Nylen S, Jones SL, Boelaert M, et al. Reassessment of immune correlates in human visceral leishmaniasis as defined by cytokine release in whole blood. Clin Vaccine Immunol 2012; 19:961-966.

35. Kushawaha PK, Gupta R, Sundar S, Sahasrabuddhe AA, Dube A. Elongation factor-2, a Th1 stimulatory protein of Leishmania donovani, generates strong IFN-gamma and IL-12 response in cured Leishmania-infected patients/hamsters and protects hamsters against Leishmania challenge. J Immunol 2011; 187:64176427.

36. Nandan D, Oliveira CC, Moeenrezakhanlou A, Lopez M, Silverman JM, Subek J, et al. Myeloid Cell IL-10 Production in response to Leishmania involves inactivation of glycogen synthase Kinase- 3 beta downstream of phosphatidylinositol-3 kinase. J Immunol 2012; 188:367-378

37. Chandra D, Naik S. Leishmania donovani infection down-regulates TLR2stimulated IL-12p40 and activates IL-10 in cells of macrophage/monocytic lineage by modulating MAPK pathways through a contact-dependent mechanism. Clin Exp Immunol 2008; 154:224-234.

38. Gautam S, Kumar R, Maurya R, Nylen S, Ansari N, Rai M, et al. IL-10 Neutralization promotes parasite clearance in splenic aspirate cells from patients with visceral leishmaniasis. J Infect Dis 2011; 204:1134-1137.

39. Ismail A, El Hassan AM, Kemp K, Gasim S, Kadaru A, Moller T, et al. Immunopathology of post kala-azar dermal leishmaniasis (PKDL): T-cell phenotypes and cytokine profile. J Pathol 1999; 189:615-622.

40. Mukhopadhyay D, Das NK, Roy S, Kundu S, Barbhuiya JN, Chatterjee M. Miltefosine effectively modulates the cytokine milieu in Indian Post Kala-Azar dermal leishmaniasis. J Infect Dis 2011; 204:1427-1436.

41. Katara GK, Ansari NA, Singh A, Ramesh V, Salotra P. Evidence for Involvement of Th17 type responses in post Kala Azar dermal leishmaniasis (PKDL). Plos Negl Trop Dis 2012; 6:e1703.

42. Yoshimura T, Takeda A, Hamano S, Miyazaki Y, Kinjyo I, Ishibashi T, et al. Two-sided roles of IL-27: Induction of Th1 differentiation on naive CD4(+)
$\mathrm{T}$ cells versus suppression of proinflammatory cytokine production including IL-23-Induced IL-17 on activated CD4(+) T cells partially through STAT3dependent mechanism. J Immunol 2006; 177:5377-5385.

43. Wu W, Huang L, Mendez S. A live Leishmania major vaccine containing CpG motifs induces the de novo generation of Th17 cells in C57BL/6 mice. Eur J Immunol 2010; 40:2517-2527.

44. Vouldoukis I, Becherel PA, RiverosMoreno V, Arock M, daSilva O, Debre P, et al. Interleukin-10 and interleukin-4 inhibit intracellular killing of Leishmania infantum and Leishmania major by human macrophages by decreasing nitric oxide generation. Eur J Immunol 1997; 27:860-865.

45. Cheekatla SS, Aggarwal A, Naik S. mTOR signaling pathway regulates the IL-12/IL-10 axis in Leishmania donovani infection. Med Microbiol Immunol 2012; 201:37-46.

46. Peruhype-Magalhaes V, Martins-Filho OA, Prata A, Silva LDA, Rabello A, Teixeira-Carvalho A, et al. Mixed inflammatory/regulatory cytokine profile marked by simultaneous raise of interferon-gamma and interleukin-10 and low frequency of tumour necrosis factor-alpha $(+)$ monocytes are hallmarks of active human visceral Leishmaniasis due to Leishmania chagasi infection. Clin Exp Immunol 2006; 146:124-132.

47. Diehl S, Rincon M. The two faces of IL- 6 on Th1/Th2 differentiation. Mol Immunol 2002; 39:531-536.

48. Yamamoto M, Yoshizaki K, Kishimoto T, Ito H. IL-6 is required for the development of Th1 cell-mediated murine colitis. J Immunol 2000 164:4878-4882.

49. Ouyang W, Filvaroff E, Hu Y, Grogan J. Novel therapeutic targets along the Th17 pathway. Eur J Immunol 2009; 39:670-675.

50. Duarte MIS, Andrade Jr HF, Takamura CFH, Sesso A, Tuon FF. TGF-beta and mesenchymal hepatic involvement after visceral leishmaniasis. Parasitology 2009; 104:1129-1136

51. Frade AF, Oliveira LC, Costa DL, Costa CHN, Aquino D, Van Weyenbergh J, et al. TGFB1 and IL8 gene polymorphisms and susceptibility to visceral leishmaniasis. Infect Genet and Evol 2011; 11:912-916.

52. Das S, Pandey K, Kumar A, Sardar AH, Purkait B, Kumar M, et al. TGF-beta(1) re-programs TLR4 signaling in L. donovani infection: enhancement of SHP-1 and ubiquitin-editing enzyme A20. Immunol Cell Biol 2012; 90:640-654.

53. Medeiros IM, Reed S, Castelo A, Salomão R. Circulating levels of sTNFR and discrepancy between cytotoxicity and immunoreactivity of TNF-alpha in patients with visceral leishmaniasis. Clin Microbiol Infect 2000; 6:34-37.

54. Duarte MIS, Tuon FF, Pagliari C, Kauffman MR, Brasil RA. Human visceral leishmaniasis expresses Th1 pattern in situ liver lesions. J Infect 2008; 57:332-337.

55. Karplus TM, Jeronimo SMB, Chang H, Helms BK, Burns TL, Murray JC, et al. Association between the tumor necrosis factor locus and the clinical outcome of Leishmania chagasi infection. Infect Immun 2002; 70:6919-6925.

56. Garg R, Barat C, Ouellet M, Lodge R, Tremblay MJ. Leishmania infantum amastigotes enhance HIV-1 production in cocultures of human dendritic cells and CD4(+) T Cells by inducing secretion of IL- 6 and TNF-alpha. Plos Negl Trop Dis 2009; $3:$ e441.

57. Ansari NA, Katara GK, Ramesh V, Salotra P. Evidence for involvement of TNFR1 and TIMPs in pathogenesis of post-kala-azar dermal leishmaniasis. Clin Exp Immunol 2008; 154:391-398.

58. Teixeira MJ, Teixeira CR, Andrade BB, Barral-Netto M, Barral A. Chemokines in host-parasite interactions in leishmaniasis. Trends Parasitol 2006; 22:32-40.

59. Sato N, Kuziel WA, Melby PC, Reddick RL, Kostecki V, Zhao WG, et al. Defects in the generation of IFN-gamma are overcome to control infection with Leishmania donovani in CC chemokine receptor (CCR) 5-, macrophage inflammatory protein-1 alpha-, or CCR2-deficient mice. J Immunol 1999; 163:5519-5525.

60. Cotterell SEJ, Engwerda CR, Kaye PM. Leishmania donovani infection initiates $\mathrm{T}$ cell-independent chemokine responses, which are subsequently amplified in a T cell-dependent manner. Eur J Immunol 1999; 29:203-214.

61. Ato M, Stager S, Engwerda CR, Kaye PM. Defective CCR7 expression on dendritic cells contributes to the development of visceral leishmaniasis. Nat Immunol 2002; 3:1185-1191.

62. Rousseau D, Demartino S, Anjuere F, Ferrua B, Fragaki K, Le Fichoux Y, et al. Sustained parasite burden in the spleen of Leishmania infantum-infected BALB/c mice is accompanied by expression of MCP-1 transcripts and lack of protection against challenge. Eur Cytokine Netw 2001; 12:340-347. 
63. Holaday BJ. Role of CD8+T cells in endogenous interleukin-10 secretion associated with visceral leishmaniasis. Mem Inst Oswaldo Cruz 2000; 95:217-220.

64. Potestio M, D'Agostino P, Romano GC, Milano S, Ferlazzo V, Aquino A, et al. CD $4(+)$ CCR $5(+)$ and CD4(+) CCR3(+) lymphocyte subset and monocyte apoptosis in patients with acute visceral leishmaniasis. Immunology 2004; 113:260-268.

65. Bimal S, Singh SK, Sinha S, Pandey K, Sinha PK, Ranjan A, et al. Leishmania donovani: role of $\mathrm{CD} 2$ on $\mathrm{CD} 4(+) \mathrm{T}$-cell function in visceral Leishmaniasis. Exp Parasitol 2008; 118:238-246.

66. Hailu A, Pater JM, Kager PA, Van der Poll T. Increased expression of HIV co-receptor CXCR4 on CD4+T-cells in patients with active visceral leishmaniasis. Scand J Infect Dis 2004; 36:56-58.

67. Petter A, Shetty-Lee A, Kofler G, Heumer HP, Larcher C. Visceral leishmaniasis in an AIDS patient on successful antiretroviral therapy: Failure of parasite eradication despite increase in CD4(+) T-cell count but low CD8(+) T-cell count. Scand J Infect Dis 2001; 33:236-238.

68. Clarencio J, Oliveira CI, Favali C-1, Medina O, Caldas A, Costa CH, et al. Could the lower frequency of CD8+CD18+CD45RO+lymphocytes be biomarkers of human VL? Int Immunol 2009; 21:137-144.

69. Maroof A, Beattie L, Zubairi S, Svensson M, Stager S, Kaye PM. Posttranscriptional regulation of $I 110$ gene expression allows natural killer cells to express immunoregulatory function. Immunity 2008; 29:295-305.

70. Rai AK, Thakur CP, Seth T, Mitra DK. Early activated Th-1 type and dominantly diverse natural killer T $(\mathrm{CD} 3(+) \mathrm{CD} 161(+) \mathrm{V}$ alpha $24(-))$ cells in bone marrow among visceral leishmaniasis patients. Int J Parasitol 2011; 41:1069-1077.

71. Alexander J, Brombacher F. Thelper $1 / t$ helper 2 cells and resistance/susceptibility to leishmania infection: is this paradigm still relevant? Front Immunol 2012;3:80.

72. Katara GK, Ansari NA, Verma S, Ramesh V, Salotra P. Foxp3 and IL-10 expression correlates with parasite burden in lesional tissues of post Kala Azar Dermal Leishmaniasis (PKDL) Patients. Plos Negl Trop Dis 2011; 5:e1171.

73. Wilke CM, Bishop K, Fox D, Zou W. Deciphering the role of Th17 cells in human disease. Trends Immunol 2011; 32:603-611.

74. Marwaha AK, Leung NJ, McMurchy AN, Levings MK. TH17 cells in autoimmunity and immunodeficiency: protective or pathogenic? Front Immunol 2012; 3:129.

75. Bending D, Newland S, Krejci A, Phillips JM, Bray S, Cooke A. Epigenetic changes at I112rb2 and Tbx21 in relation to plasticity behavior of Th17 Cells. J Immunol 2011; 186:3373-3382.

76. Charmoy M, Auderset F, Allenbach C, Tacchini-Cottier F. The prominent role of neutrophils during the initial phase of infection by Leishmania Parasites. J Biomed Biotechnol 2010; 2010:719361.

77. Lopez Kostka S, Dinges S, Griewank K, Iwakura Y, Udey MC, von Stebut E. IL-17 promotes progression of cutaneous leishmaniasis in susceptible mice. J Immunol (Baltimore, Md: 1950) 2009; 182:3039-3046.

78. Vargas-Inchaustegui DA, Xin L, Soong L. Leishmania braziliensis infection induces dendritic cell activation, ISG15 transcription, and the generation of protective immune responses. J Immunol 2008; 180:7537-7545.
79. Castilho TM, Goldsmith-Pestana K, Lozano C, Valderrama L, Saravia NG, McMahon-Pratt D. Murine model of chronic L. (Viannia) panamensis infection: Role of IL-13 in disease. Eur J Immunol 2010; 40:2816-2829.

80. Boaventura VS, Santos CS, Cardoso CR, de Andrade J, dos Santos WLC, Clarencio J, et al. Human mucosal leishmaniasis: Neutrophils infiltrate areas of tissue damage that express high levels of Th17-related cytokines. Eur J Immunol $2010 ; 40: 2830-2836$.

81. Agallou M, Margaroni M, Karagouni E. Cellular vaccination with bone marrowderived dendritic cells pulsed with a peptide of Leishmania infantum KMP-11 and $\mathrm{CpG}$ oligonucleotides induces protection in a murine model of visceral leishmaniasis. Vaccine 2011; 29:5053-5064.

82. Fitzgerald DC, Ciric B, Touil T, Harle H, Grammatikopolou J, Das Sarma J, et al. Suppressive effect of IL-27 on encephalitogenic Th17 cells and the effector phase of experimental autoimmune encephalomyelitis. J Immunol 2007; 179:3268-3275.

83. McKinstry KK, Strutt TM, Buck A, Curtis JD, Dibble JP, Huston G, et al. IL-10 deficiency unleashes an influenza-specific Th17 response and enhances survival against high-dose challenge. J Immunol 2009; 182:7353-7363.

84. Anderson CF, Stumhofer JS, Hunter CA, Sacks D. IL-27 Regulates IL-10 and IL-17 from CD4(+) Cells in nonhealing Leishmania major infection. J Immunol 2009; 183:4619-4627.

85. Rosas LE, Satoskar AA, Roth KM, Keiser TL, Barbi J, Hunter C, et al. Interleukin-27R (WSX-1/T-cell cytokine receptor) gene-deficient mice display enhanced resistance to Leishmania donovani infection but develop severe liver immunopathology. Am J Pathol 2006; 168:158-169.

86. Murray HW, Nathan CF. Macrophage microbicidal mechanisms in vivo: Reactive nitrogen versus oxygen intermediates in the killing of intracellular visceral Leishmania donovani. J Exp Med 1999; 189:741-746.

87. Murray HW, Xiang ZY, Ma XJ. Short report: Responses to Leishmania donovani in mice deficient in both phagocyte oxidase and inducible nitric oxide synthase. Am J Trop Med Hyg 2006; 74:1013-1015.

88. White JK, Mastroeni P, Popoff JF, Evans CAW, Blackwell JM. Slc111a1mediated resistance to Salmonella enterica serovar Typhimurium and Leishmania donovani infections does not require functional inducible nitric oxide synthase or phagocyte oxidase activity. J Leukoc Biol 2005; 77:311-320.

89. Perez LE, Chandrasekar B, Saldarriaga OA, Zhao W, Arteaga LT, Travi BL, et al. Reduced nitric oxide synthase 2 (NOS2) promoter activity in the Syrian hamster renders the animal functionally deficient in NOS2 activity and unable to control an intracellular pathogen. J Immunol 2006; 176:5519-5528.

90. Biswas A, Bhattacharya A, Kar S, Das PK. Expression of IL-10-triggered STAT3-dependent IL-4R alpha is required for induction of arginase 1 in visceral leishmaniasis. Eur J Immunol 2011; 41:992-1003.

91. Schleicher U, Liese J, Knippertz I, Kurzmann C, Hesse A, Heit A, et al. NK cell activation in visceral leishmaniasis requires TLR9, myeloid DCs, and IL-12, but is independent of plasmacytoid DCs. J Exp Med 2007;204:893-906.

92. Elshafie AI, Ahlin E, Hakansson LD, Elghazali G, El Safi SH, Ronnelid J, et al. Activity and turnover of eosinophil and neutrophil granulocytes are altered in visceral leishmaniasis. Int J Parasitol 2011; 41:463-469. 